\title{
Water supply system decision making using multicriteria analysis
}

\author{
Danielle C Morais* and Adiel T Almeida \\ Federal University of Pernambuco, PO Box 7462, Recife-PE; 50630-970, Brazil
}

\begin{abstract}
Sound decision-making processes for investments in water supply systems need to be developed. This need arises from the problem observed in developing countries of a growing demand for water supply projects coupled with a lack of financial resources available to invest in them. A second problem is the selection of a locality that is most in need of assistance for the implementation of the water supply system. This study describes the application of multicriteria decision aid for choosing the priority city to receive a water supply system, using the ELECTRE methodology. It was found that this type of methodology accommodates the decision-making in selecting a locality, with the capacity to integrate weighted qualitative judgment criteria, incorporating the concordance and discordance indices, specifying an efficient allocation of resources available and thus maximising gains.
\end{abstract}

Keywords: investment justification, multicriteria analysis, water supply

\section{Introduction}

Nowadays some basic factors contribute to the problems of managing urban water supply systems, for example, a shortage of resources available to develop the basic infrastructure at the same time as there is an increased demand for basic sanitation systems. Various municipal districts in developing countries exemplify this situation, where there is competition for scarce funds at the same time as an increased need for water provision, with a reduced quality of life because of the lack of water supply systems.

The question then is this: when there are limited resources available for basic sanitation projects, how can a decision be made as to which is the best city for an enterprise to invest in, using the funds available.

With respect to the question of water supply, the North-East Region of Brazil is a critical area, with all towns and cities in the region clamouring for full or partial improvement in the operation and maintenance of their existing systems or even do not have any kind of water supply system.

Those responsible for the planning and allocation of resources for the basic sanitation sector have their hands tied, because they do not have an appropriate decision-making model that can help them match the strategic plans of their companies to the needs of the region (Biswas et al., 1980).

According to Gough and Ward (1996), the major characteristics of environmental decision making, for example in the provision of water supply systems, are the existence of considerable uncertainty, the potential for decisions that lead to irreversible outcomes and the likelihood of multiple decision makers and multiple criteria. Under these circumstances, multicriteria decision analysis provides a way of structuring complex decision problems so as to enhance the process of improving the likelihood of positive outcomes. This paper deals with the allocation

\footnotetext{
* To whom all correspondence should be addressed.

푤 +55 81 2126-8728 ext 29; fax: +55 81 2126-8728 ext 30;

e-mail: dcmorais@ufpe.br

Received 4 July 2005; accepted in revised form 20 January 2006
}

of resources for water supply applying the ELECTRE method in order to choose the city in which the project will be implemented, in agreement with specific criteria that are usually conflicting. This method can provide solutions to increasingly complex water supply management problems. While traditional single-criteria decision making is usually aimed at maximising the benefits while minimising the costs, this method provides a better understanding of the inherent features of the decision problem, promoting the role of participants in decision making processes, facilitating compromise and collective decisions and providing an adequate platform for understanding the perception of models and analysts within a realistic scenario. Moreover, this method assists in improving the quality of decisions by making them more explicit, rational and efficient.

\section{Multicriteria decision aid}

Decisions are part of people's day-by-day behaviour. This is quite a complex, although almost unperceived activity, in which possible actions, points of view and specific forms of evaluation are involved, in other words, a multiplicity of factors (Gomes et al., 2002). Nowadays the most common form of decision making is based on intuition, called intuitive judgment, when the components of the problem analysis are not considered in an organised way.

The relevance of the multicriteria decision-aid methodology stems from the fact that in most situations when people are making a decision, they do not have only one objective; instead, they need to take into consideration a number of different points of view. Towards this, multicriteria methods may be used to guide the analysis by specifying the criteria involved in the decision to suggest a priority of choices among the alternatives.

Multicriteria decision making (MCDM) is a branch of a general class of operations research models, which deals with decision problems when a number of decision criteria are present (Zeleny, 1982). There are several methods, which can be used according to the type of problem, such as choice-based, rankingbased and sorting-based. Mixed methods can also be applied. Each method has its own characteristics. 


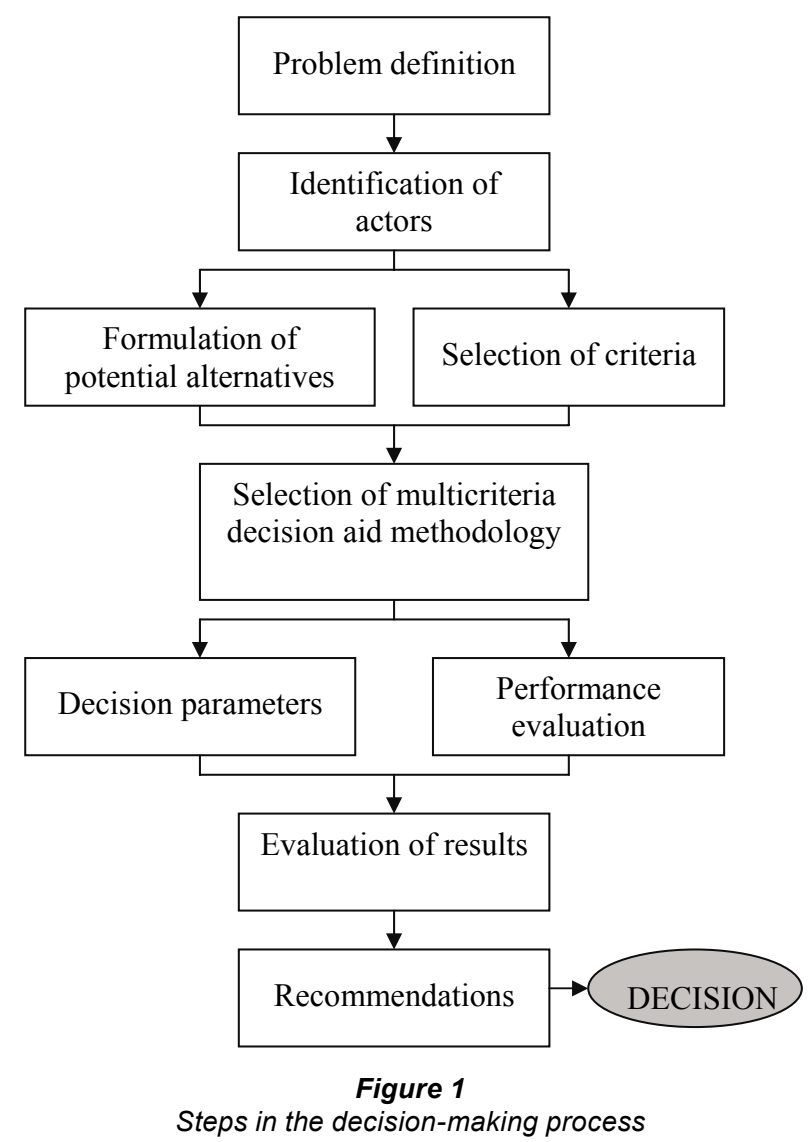

According to Vincke (1992), the adoption of one of these methods is usually justified by arguments dictated by the nature of the problem to be analysed. In multicriteria methodology, a small number of alternatives are evaluated against a set of criteria that are often hard to quantify. The alternatives are usually selected by making comparisons between each other with respect to each criterion. The multicriteria decision process is shown in Fig. 1.

The foundations for the decision-making methodology based on the outranking relation concept were established by Bernard Roy, through the development of the ELECTRE family of methods (the acronym of which means ELimination Et Choix Traduisant la REalité, translated into English as Elimination and Choice Expressing the Reality) (Roy, 1996). Since then, this method has been widely used by MCDM researchers, mainly in Europe, and has proved useful as an aid to decision making in numerous applications (e.g. Al-Kloub et al., 1997; Al-Rashdan et al. 1999; Dotto et al., 1996; Duckstein et al., 1982; Lamy et al., 2002; Salmine et al., 1998; Zopounidis and Doumpos, 2002).

The ELECTRE family of methods explores comparisons among alternatives, in pairs. ELECTRE I was the first method to employ the outranking relation concept. Since then, several extensions have been proposed, including ELECTRE II, III, IV, IS and TRI (Olson, 1996). These methods address different types of problems, including:

- Choice (ELECTRE I, IS): tries to shrink the number of alternatives presented for consideration. (Roy (1996) represents choice problematic as P. $\alpha$ )

- Ranking (ELECTRE II, III, IV): results in an ordination of alternatives not dominated. (Roy (1996) represents ranking problematic as P. $\gamma$ )

- Sorting (ELECTRE TRI): shows a classification of alternatives according to specific parameters. (Roy (1996) represents sorting problematic as P. $\beta$ ).
To sum up, this methodology establishes a relationship that accompanies the parameters set by the decision makers, to reduce the number of potential alternatives using the concept of dominance. Being non-compensatory, the method requests inter-criteria information that reflects the relative importance of the objectives established, in other words, the weight of each criterion. These weights may be established from technical calculations or as expressions of judgement value. Thus, the method provides well-balanced actions.

In this paper, the outranking method ELECTRE I will be used, as it is a method devised to deal with action choices in multicriteria problems, and the problem to be analysed is to select the city in which to implement the water supply system, based on specific criteria defined by the actors involved in the process. The actors are those who assess the objectives and express preferences and have an interest in imposing them on the evolution of the process. They are also called stakeholders or decision makers and usually might be relatively diverse, having different objectives and conflicting value systems (Roy, 1996).

According to Roy (1996), the method ELECTRE I aims therefore to be able to obtain a subset $N$ of actions such that any action which is not in $N$ is outranked by at least one action of $N$. The latter subset (which will be made as small as possible) is thus not the set of the best actions, because there is no action which is better than all the others for all the criteria considered simultaneously (the concept of optimal solution does not make any sense in a multicriteria context), but it is the set in which the best compromise may be found.

The main idea behind the ELECTRE I method is to eliminate subsets of less desirable alternatives and select alternatives more preferable among the majority of criteria considered. For this, it assumes that one solution is preferred to another if there are sufficient advantages and no significant disadvantages. It aids in calculating the degree to which one solution is better (concordance index) and/or worse (discordance index) than the other. Then, the method seeks a solution that is at least as good as another solution for a majority of criteria.

A concordance and discordance index is associated for each ordered pair of actions $(\mathrm{a}, \mathrm{b})$. The concepts are introduced below (Vincke, 1992):

\section{Concordance Index $-C(a, b) \in[0,1]$}

The concordance index takes its values between 0 and 1 , and can be seen as measuring the arguments in favour of the statement ' $a$ outranks $b$ ' (denoted by aSb). This index identifies the strength of affirmation: $\mathrm{F}=$ 'alternative $a$ is at least as good as alternative $b$. The closer $C$ is to unity, the higher the strength of the arguments that support the affirmation F. The concordance index is estimated as follows:

$$
C(a, b)=\frac{1}{W_{j:: g_{j}(a) \geq g_{j}(b)}} w_{j} \quad \text { where } \mathrm{W}=\sum_{\mathrm{j}=1}^{\mathrm{n}} \mathrm{w}_{\mathrm{j}}
$$

where:

$g_{j}(a)$ is the value or performance of alternative $a$ in relation to criterion $j(\mathrm{j}=1, \ldots, \mathrm{n})$

$\mathrm{n}=$ number of criteria considered

$w_{j}=$ weight of the criteria $\mathbf{j}$

$C(a, b)=$ the sum of the weights associated to the criteria whose value of $g_{j}(a) \geq g_{j}(b)$, which represents the strength of the arguments that support the affirmation $\mathrm{aSb}$.

Roy (1996) states that for each criterion a weight should be assigned, increasing with the importance of the criterion, in other words, representing its relative importance. 
Discordance Index $-D(a, b) \in[0,1]$

The discordance index also takes its values between 0 and 1 and evaluates the strength of the arguments against the affirmation F. The higher the discordance index (D) the more significant is the opposition of the criteria to the validity of the affirmation F. Therefore, among the criteria in favour of $b$, some may shed some doubt upon the statement ' $a$ outranks $b$ ', and this phenomenon is represented by a discordance index. The discordance index is estimated as follows:

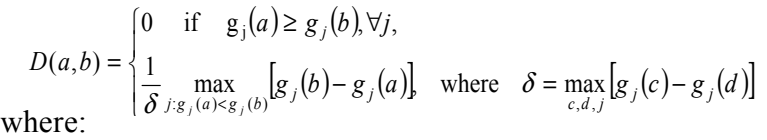

$D(a, b)$ is the maximum difference between $g(b)$ and $g(a)$ for all criteria $(j)$ where $g(b)>g(a)$ divided by the interval of scale of the criterion considered. Thus, this index increases if the preference of $b$ over $a$ becomes very large for at least one criterion.

$\delta=\max \left\lfloor g_{j}(c)-g_{j}(d)\right\rfloor$ is an interval of scale of the criterion $\mathrm{j}$ (the criterion that had the maximum difference between $g(b)$ and $g(a))$, in other words, size of larger scale, where max corresponds to the larger algebraic difference and $g_{j}(c)$ and $g_{j}(d)$ represents the best and the worst performance in criterion $\mathrm{j}$, respectively.

\section{Outranking relation $-\mathrm{S}$}

Once the concordance and discordance indices are established, their results are combined to construct the final outranking relationship. To interpret the information contained in concordance and discordance matrices, threshold values ( $p$ and $q$ ) are defined by the decision makers to specify the amount of desired concordance and tolerated discordance. The technique comprises the establishment of concordance and discordance levels stating that a dominance hypothesis is justified. This combination is performed as follows:

$$
\begin{aligned}
a S b \rightarrow C(a, b) & \geq p \\
\mathrm{D}(\mathrm{a}, \mathrm{b}) & \leq \mathrm{q}
\end{aligned}
$$

where:

$p$ is the concordance threshold

$q$ is the discordance threshold

Solutions with values above the concordance threshold $p$, and below the discordance threshold $q$ are subjected to pair-wise comparisons. Solutions with intermediate concordance and discordance indices are said to be not comparable. The actors involved in the process decide the values for $p$ and $q$.

\section{Structuring the problem}

This section deals with structuring the problem by defining the alternatives, the actors and the criteria, being introduced as the measurement scales of the criteria.

\section{Current situation}

The North-East is the poorest region of Brazil, considered undeveloped. Most of the region's inhabitants reside on semi-arid land, severely affected by the natural phenomenon of drought, which is one of the principal problems faced by the population. The absence of environmental sanitation policies has contributed to the deterioration in the quality of life. It is not rare to observe cases of epidemic diseases related to a lack of hygiene and clean drinking water (Morais and Almeida, 2002).

The problem of water-borne diseases is of grave concern because of the impact on society. The local population has demanded immediate actions from the directors of public companies regarding the delivery of a water supply system, which will provide inhabitants with potable water of an acceptable quality. According to Martins et al. (2001), with such system in place, diseases such as shigellosis, amoebiasis and taeniasis could be reduced by about $50 \%$. At the same time, ascariasis and schistosomiasis could be reduced by about $40 \%$ and $60 \%$ respectively.

Cholera, typhoid fever and hepatitis are also water-borne diseases. These diseases are the only ones that the local health authorities are required to report. Diseases such as gastroenteritis, worms and infectious diarrhoea are ignored by the authorities, the number of cases of those diseases being unknown. These data reveal the importance of the actions to supply water of an appropriate quality in order to provide a better quality of life for the population.

It is a proven fact that investment in sanitation, even where the return on investment is lower than the capital cost, is vital in order to reduce public health expenditure, for example with respect to the reduction of the use of medicines and the need for hospitalisation. Ximenes et al. (2003) state that the relationship coefficient among those factors is considered to be in the order of 1:4, in other words, for each R $\$ 1.00$ (one Brazilian real) invested in the sanitation division, $\mathrm{R} \$ 4.00$ (four Brazilian reais) are saved in the area of public health.

When these investments do not materialise, or when they are inappropriately applied, is often a result of a lack of the appropriate tools for government planning. How, where, when and why to intervene are questions raised, but unanswered.

\section{The alternatives}

This study will look at a number of cities within Pernambuco, a state located in the North-East Region of Brazil, using the methodology proposed in the work presented here which is based on the ELECTRE I method, to choose which municipal district might be considered for the provision of a water supply system. The development plan for water supply in the State of Pernambuco was based on eight municipal districts, but the implementation can only be done by one. Thus, it is important to choose the particular district that is most in need of assistance at that particular moment, where the provision of a water supply system will maximise health, social, economic, environmental and other benefits.

The potential alternatives are the following municipal districts (Fig. 2): Alianca (A1), Moreno (A2), Ouricuri (A3), Passira (A4), Pocao (A5), Porto de Galinhas (A6), Toritama (A7), Trindade (A8). All these districts had already had their projects designed with defined implementation costs.

\section{The actors and the criteria}

Some difficulties in selecting the appropriate city for the provision of a water supply system are social impact, compatibility with political goals and environmental impact. Interest groups, who are called actors, represent each of these aspects.

In Pernambuco, the actual decision makers in this kind of problem are the local municipal government coupled with the state water company, which holds the water concession in the majority of the cities in this state. The points of view of the local 


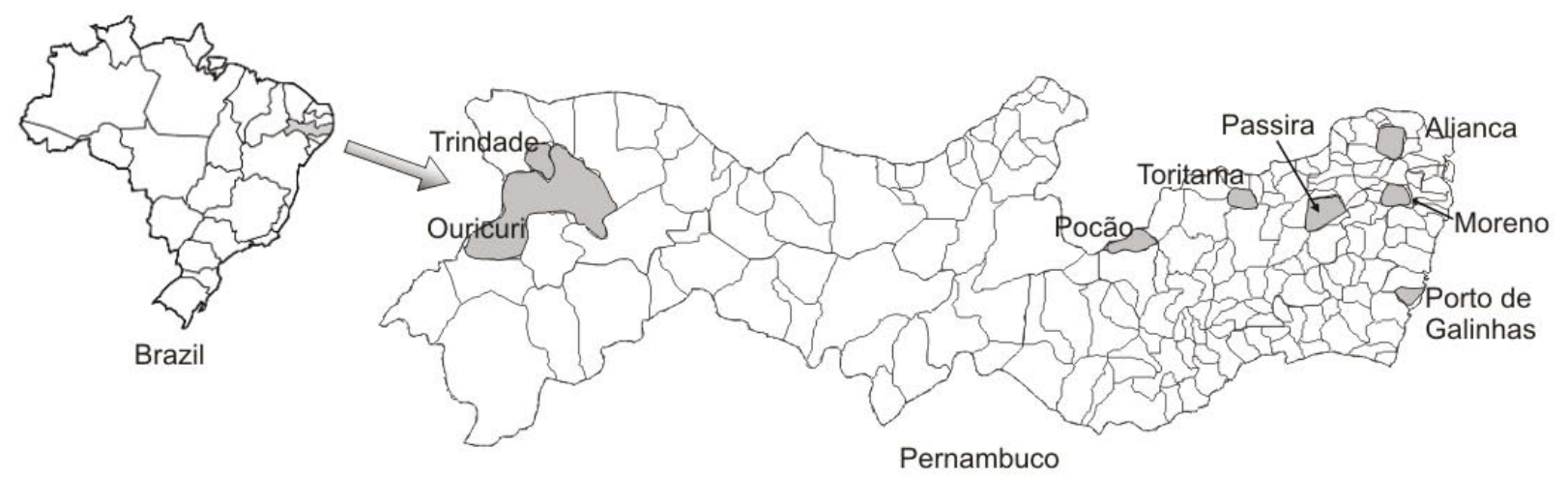

Figure 2

Location of the potential districts

environmental agency, development bank, local citizens and other interest groups, however, must be considered, making the case more complex. Each one has its own objectives and criteria, which is a source of constant disagreement.

This question of involving a group of agents in the decisionmaking process is important as an element in the definition of parameters and guidelines to establish the norms of decision making. In this case, some groups with different interests were identified, to guide the definition of criteria and to determine the chosen process to select the most deserving locality to be granted a water supply system.

The interest groups that were considered in this study were as follows:

- Water company that traditionally acts as the organ of implementation of the system

- Environmental agency, which is responsible for making sure that the project is designed so that the environment is protected

- Local groups such as local commerce, local industrial park, hotels and other representatives of the economy and the local community. These people can actively influence the decisions to support their own interests.

In addition, there are some entities tied to the government of the state with enough power to influence the decisions. In terms of financial aspects, bankers can impose pressure in favour of their own interests. Some of the players are Caixa Economica Federal (Federal Bank) and The Interamerican Development Bank.

It should also be noted that each decision group has an opinion and a specific interest. Therefore, conflicts can be generated due to a series of factors. It is clear that what is needed is a simplified methodology for the choice of the locality for the provision of a water supply system, by evaluating several aspects. The process of multicriteria selection was used (ELECTRE I) with scientifically generated information able to show the clearest route for enterprise implementation based on the expectation that the health of the affected population would improve as a result of potable water service delivery.

Some meetings were arranged with these interest groups. In these meetings, they had the opportunity to express the points and list the factors they perceived to be sufficiently important to be taken into account in the selection process. In this context, the aspects that the actors considered important for the evaluation of the alternatives can be classified as follows:

- Economic factor: Cost of investment (Cr1)

- Social factor: Population benefit with the project $(\mathrm{Cr} 2)$

- Environmental factor: Quality of life (Cr3)

- Political factor: Tourism in the city (Cr4)
Each of these was measured according to the points of view of the decision makers. Some of these were difficult to measure, and this is one of the reasons for using multicriteria decision aid. The use of this methodology may be helpful in preserving all the information obtained.

\section{Measuring the criteria and the alternatives}

This section describes how the value of each criterion was measured:

\section{Cost of investment (Cr1)}

The cost of investment was estimated based on the water supply project designed for each municipal district.

\section{Population (Cr2)}

In this context, the population is the number of inhabitants served by the project, in other words, the number of beneficiaries of the project. The larger the population benefiting from the provision of a water supply system, the more preferable will be the alternative (locality) to be granted such system.

\section{Quality of life (Cr3)}

With enterprises of this magnitude, there will be a substantial improvement in the sanitation and hygiene conditions of the population, and concomitant better quality of life. The indicator used will be the Life Conditions Index (LCI), obtained through data from FIDEM, a Brazilian Foundation, which studies metropolitan development. This index is intimately related to the sanitation conditions and it increases when the quality of life is improved. For example, the LCI for Brazil is 0.723 , while that for Pernambuco is 0.616 (Fidem, 2000). Thus, the cities that have the lowest LCI will be given preference.

\section{Tourism (Cr4)}

An improvement in the basic infrastructure of a city will boost the tourism industry and the increasing number of hotels, lodgings, and restaurants, will leverage the local economy.

For this criterion, the alternatives are evaluated using qualitative measures and converted to numeric scale (e.g. a scale of 0tol, where 0 represents "weak" and 1 represents "very good"). The actors evaluated this criterion based on the city's position in respect of tourism. For instance, if the city is not actively committed to developing tourism, the delivery of a water supply system will not assist it in developing economically, so the impact of the system delivery will be weak in terms of tourism leverage. Thus, the cities that have the greatest tourism potential will be given preference. The values attributed to each concept are shown in Table 1 . 


\section{Relevance among the criteria}

To establish the relevance among the criteria, a weight was assigned to each criterion. In a broad sense, weights are forms of representation of the preferences of the decision makers (Choo et al., 1999). They can be technical calculations or expressions of value judgment.

In this study, the importance of each criterion was estimated by the actors involved in the form of weights that were established by an inquiry. The actors were asked to evaluate the importance of each criterion on a scale of 1 to 5. After that, the median of the weights for a certain criterion was chosen to be its final weight. The use of the average values of the weights, however, would not have influenced the result, because the differences between them and the median values were very small. The practical reason for using this kind of simple version for obtaining weights comes from the fact that it was not possible to use any method which requires computers for each actor, and also the actors were not prepared to give themselves enough time to make use of more sophisticated methods possible in this phase. In general, they found it easy to divide the criteria into the groups having more or less similar weight/importance. However, within these groups the comparison of importance was found to be difficult.

In agreement with the established guidelines for the decision makers, the parameters designated are shown in Table 2.

The greatest weight in this case is for the criteria dealing with the cost of investment. Although it is clear that these values somehow reflect the collective importance of the criteria, they cannot be regarded as precise values. Therefore, a sensitivity analysis of these weights is necessary. An overview of the values related with the evaluation of alternatives in relation with the criteria, is presented for the current conditions of each municipal district in Table 3.

\section{Results}

\section{Calculation of the indices}

Having all the values of each alternative for the criteria, properly normalised, the concordance and discordance indices among the alternatives can be calculated. Tables 4 and 5 present these indices.

\section{Establishing the concord- ance $(p)$ and discordance $(q)$ thresholds}

The key to the procedure is the limits required for concordance and discordance dominance. Parameters $p$ and $q$ are provided by the decision maker to set bounds on required concordance and discordance to identify dominance relationships. These thresholds allow the consideration of the imprecise and intrinsic nature of the evaluations for investment to provide a water supply system for a specific locality in the light of the criteria under consideration.

The concordance threshold is a number that would be advantageous only for the decision maker for those alternatives that obtained values above the established number. In a similar way, the discordance threshold represents the percentile that does not have an advantage for the decision maker for those alternatives

\begin{tabular}{|c|c|}
\hline \multicolumn{2}{|c|}{ TABLE 1 } \\
Quantifying tourism benefits \\
\hline Concept & Numeric scale \\
\hline Weak & 0.00 \\
\hline Regular & 0.33 \\
\hline Good & 0.67 \\
\hline Very good & 1.00 \\
\hline
\end{tabular}

\begin{tabular}{|l|l|l|l|}
\hline \multicolumn{4}{|c|}{ TABLE 2 } \\
Relevance among criteria - weights \\
\hline Cost & Population & Tourism & Quality of life \\
\hline 0.30 & 0.25 & 0.25 & 0.20 \\
\hline
\end{tabular}

TABLE 3

Evaluation of alternatives in relation to criteria ALTERNATIVES

\begin{tabular}{|c|c|c|c|c|} 
& \multicolumn{4}{|c|}{} \\
\cline { 2 - 5 } & Cost (R\$*) & Population & Quality of life & Tourism \\
\hline A1 & 589176 & 37188 & 0.476 & - \\
\hline A2 & 1548354 & 45481 & 0.600 & 0.33 \\
\hline A3 & 2053485 & 56623 & 0.443 & - \\
\hline A4 & 804270 & 29131 & 0.474 & 0.33 \\
\hline A5 & 2191952 & 11177 & 0.478 & 0.67 \\
\hline A6 & 5181246 & 10995 & 0.500 & 1.00 \\
\hline A7 & 2135702 & 21794 & 0.600 & - \\
\hline A8 & 1457073 & 21919 & 0.496 & - \\
\hline
\end{tabular}

* $\mathrm{R} \$=$ Brazilian real $(\mathrm{R} \$ 2.50=\mathrm{US} \$ 1.00)$

\begin{tabular}{|l|c|c|c|c|c|c|c|c|}
\hline \multicolumn{1}{|c|}{ Concordance index } \\
\hline & A1 & A2 & A3 & A4 & A5 & A6 & A7 & A8 \\
\hline A1 & - & 0.300 & 0.625 & 0.750 & 0.550 & 0.550 & 0.550 & 0.550 \\
\hline A2 & 0.700 & - & 0.750 & 0.575 & 0.750 & 0.750 & 0.775 & 0.575 \\
\hline A3 & 0.375 & 0.250 & - & 0.250 & 0.550 & 0.550 & 0.550 & 0.250 \\
\hline A4 & 0.250 & 0.425 & 0.750 & - & 0.550 & 0.550 & 0.675 & 0.675 \\
\hline A5 & 0.450 & 0.250 & 0.450 & 0.450 & - & 0.550 & 0.250 & 0.250 \\
\hline A6 & 0.450 & 0.250 & 0.450 & 0.450 & 0.450 & - & 0.250 & 0.450 \\
\hline A7 & 0.450 & 0.225 & 0.450 & 0.325 & 0.750 & 0.750 & - & 0.325 \\
\hline A8 & 0.450 & 0.425 & 0.750 & 0.325 & 0.750 & 0.550 & 1.000 & - \\
\hline
\end{tabular}

\begin{tabular}{|l|c|c|c|c|c|c|c|c|}
\hline \multicolumn{10}{|c|}{ DABLE 5 } \\
Discordance index \\
\hline & A1 & A2 & A3 & A4 & A5 & A6 & A7 & A8 \\
\hline A1 & - & 0.790 & 0.426 & 0.330 & 0.660 & 1.000 & 0.790 & 0.330 \\
\hline A2 & 0.209 & - & 0.244 & 0.162 & 0.330 & 0.670 & - & 0.020 \\
\hline A3 & 0.319 & 1.000 & - & 0.330 & 0.660 & 1.000 & 1.000 & 0.338 \\
\hline A4 & 0.177 & 0.803 & 0.603 & - & 0.330 & 0.670 & 0.803 & 0.140 \\
\hline A5 & 0.570 & 0.777 & 0.996 & 0.393 & - & 0.340 & 0.777 & 0.235 \\
\hline A6 & 1.000 & 0.791 & 1.000 & 0.953 & 0.651 & - & 0.663 & 0.811 \\
\hline A7 & 0.337 & 0.519 & 0.763 & 0.290 & 0.330 & 0.670 & - & 0.148 \\
\hline A8 & 0.335 & 0.662 & 0.761 & 0.158 & 0.330 & 0.670 & 0.662 & - \\
\hline
\end{tabular}


with values below this number. In other words, $p$ specifies the minimum concordance index required for outranking whereas $q$ defines the maximum discordance index needed for outranking, that the decision maker is willing to accept. The values for both threshold $(p, q)$ parameters are between 0 and 1 and were selected by the decision makers as follows:

Concordance threshold: $p=.55$

Discordance threshold: $q=.44$

\section{Analysing kernel}

The final stage consists of determining the kernel, starting with the outranking relationships, and going through the comparison of the concordance and discordance indices calculated using the two parameters $p$ and $q$. Table 6 presents the result.

\begin{tabular}{|l|c|c|c|c|c|c|c|c|c|c|}
\hline \multicolumn{10}{|c|}{ TABLE 6 } \\
\hline A1 & $>$ & $\{-$ & - & A3 & A4 & - & - & - & A8 $\}$ \\
\hline A2 & $>$ & $\{$ A1 & - & A3 & A4 & A5 & - & A7 & A8 $\}$ \\
\hline A3 & $>$ & $\{-$ & - & - & - & - & - & - & - \\
\hline A4 & $>$ & $\{-$ & - & - & - & A5 & - & - & A8 $\}$ \\
\hline A5 & $>$ & $\{-$ & - & - & - & - & A6 & - & - \\
\hline A6 & $>$ & $\{-$ & - & - & - & - & - & - & - \\
\hline A7 & $>$ & $\{-$ & - & - & - & A5 & - & - & - \\
\hline A8 & $>$ & $\{-$ & - & - & - & A5 & - & - & - \\
\hline
\end{tabular}

Alternative A2 (Moreno) was not outranked by any other alternative. Kernel initial $=\{$ Moreno $\}$.

The alternatives outranked for Moreno were eliminated. Nonkernel $=\{$ Aliana, Ouricuri, Passira, Pocao, Toritama, Trindade\}.

The alternative Porto de Galinhas (A6) was not outranked by Moreno, but was outranked by another alternative (A5), and so the result is:

Kernel $=\{$ Moreno $\}$

Non-kernel $=\{$ Aliana, Ouricuri, Passira, Pocao, Porto de Galinhas, Toritama, Trindade\}

\section{Robustness analyses}

Using the individual results of each municipal district, based on the established criteria, the degree of quality of each alternative is evaluated, and then an analysis of the sensibility of the considered thresholds is also made, in order to have a more robust result. An overview of this robustness analysis is shown in Table 7.

\begin{tabular}{|l|l|l|l|l|l|l|l|l|l|}
\hline \multicolumn{10}{|c|}{ TABLE 7 } \\
\hline $\mathrm{p}$ & $\mathrm{q}$ & $\mathrm{A} 1$ & $\mathrm{~A} 2$ & $\mathrm{~A} 3$ & $\mathrm{~A} 4$ & $\mathrm{~A} 5$ & $\mathrm{~A} 6$ & $\mathrm{~A} 7$ & $\mathrm{~A} 8$ \\
\hline .55 & .44 & & $\mathrm{x}$ & & & & & & \\
\hline .55 & .64 & & $\mathrm{x}$ & & & & & & \\
\hline .55 & .24 & & $\mathrm{x}$ & $\mathrm{x}$ & & $\mathrm{x}$ & $\mathrm{x}$ & & \\
\hline .75 & .44 & $\mathrm{x}$ & $\mathrm{x}$ & & & & $\mathrm{x}$ & & $\mathrm{x}$ \\
\hline .35 & .44 & & $\mathrm{x}$ & & & & & & \\
\hline
\end{tabular}

This analysis having been accomplished, it can be observed that in the first simulation, for $p=.55$ and $q=.44$ (the original values defined by the decision makers), only one alternative was selected (A2: Moreno). It shows that even with the variation of $20 \%$ in the discordance threshold for more $(q=.64)$ and for less $(q=.24)$, consequently making the evaluation more and less difficult, this initially selected alternative was maintained.
To complement this analysis, variations of around $20 \%$ in the agreement threshold were also evaluated, and the result is not very different: the nucleus continues to indicate the location of Moreno as the most satisfactory place to receive the investment to implement a water supply system.

According to Olson (1996) the results of the analysis can be quite sensitive to the settings for $p$ and $q$. Thus, multiple ELECTRE should be run varying $p$ and $q$ to be viewed as slicing planes. Moreover, it is relevant to know that this approach depends upon two sets of parameters assumed given by the decision maker. First, both concordance and discordance indices depend upon the relative criteria weights. Second, dominance relationships depend upon the limits of $p$ and $q$.

\section{Conclusions}

The selection of an appropriate place for the provision of a water supply system is complicated and complex due to the growing demand coupled to the shortage of financial resources.

By helping to organise the decision-making process multicriteria decision-aid support tools can assist decision makers in making appropriate decisions to allocate funds for those most in need of assistance. Therefore, water resource and sanitation planning using multicriteria analysis methodology has attracted the attention of decision makers. It has been demonstrated that the method can provide solutions for complex water decisionmaking problems.

The use of the ELECTRE I method in this present case study for the selection of a locality for the provision of a water supply system is based on objectives and inter-criteria information supplied by the decision makers. The decision model includes criteria relying on interdisciplinary principles, such as economics, environmental aspects, human health risks and social perception. This method turns out to be an appropriate approach for these kinds of situations, suggesting the alternative with better compromise, being well balanced.

The use of this method, instead of intuitive judgments, assisted in improving the quality of the decision by making it more explicit, rational and efficient.

\section{References}

AL-KLOUB B, AL-SHERMMERI T and PEARMAN A (1997) The role of weights in multicriteria decision aid, and the ranking of water projects in Jordan. Eur. J. Oper. Res. 99 (2) 278-288.

AL-RASHDAN D, AL-KLOUB B, DEAN A and AL-SHERMMERI T (1999) Environmental impact assessment and ranking the environmental projects in Jordan. Eur. J. Oper. Res. 118 (1) 30-45.

BISWAS AK, SAMASHA MAH, AMER MH and ABU-ZEID M (1980) Water Management for Arid Lands in Developing Countries. Water Development, Supply and Management. Vol. 13. Pergamon Press.

CHOO U, SCHONER B and WEDLEY C (1999) Interpretation of criteria weights in multicriteria decision making. Comput. Ind. Eng. 37 (3) 527-541.

DOTTO SE, SINGER EM and SANTOS RF (1996) The selection and the hierarchical classification of water quality parameters for irrigated crops through an ELECTRE I and II. Bragantia 55 (1) 185-192.

DUCKSTEIN L, GERSHON M and MCANIFF R (1982) Model selection in multiobjective decision making for river basin planning. $A d v$. Water Resour. 5 (3) 178-184.

FIDEM-PE (2000) Foundation of Metropolitan Development of the Pernambuco State. Research of Quality of Life. Perfil Municipal. Governo do Estado de Pernambuco, Recife.

GOMES LFAM, GOMES CFS and ALMEIDA AT (2002) Tomada de Decisão Gerencial: Enfoque Multicritério. Atlas, Rio de Janeiro. 
GOUGH JD and WARD JC (1996) Environmental decision making and lake management. J. Environ. Manage. 48 (1) 1-15.

LAMY F, BOLTE J, SANTELMANN M and SMITH C (2002) Development and evaluation of multiple-objective decision-making methods for watershed management planning. J. Am. Water Resour. Assoc. 38 (2) 517.

MARTINS G, BORANGA JA, LATORRE MRDO and PEREIRA HASL (2001) Impacto do saneamento básico na saúde da população. Proc. $21^{\text {st }}$ Cong. Bras. Eng. Sanitária e Ambiental. João Pessoa, Paraíba, Brasil.

MORAIS DC and ALMEIDA AT (2002) Multicriteria decision-aid for implementation of water supply system. Proc. MIM 2002: $5^{\text {th }}$ Int Conf. on Managing Innovations in Manufacturing (MIM). Milwaukee, Wisconsin, USA.

OLSON DL (1996) Decision Aids for Election Problems. Springer Verlag, New York.
ROY B (1996) Multicriteria Methodology for Decision Aiding. Kluwer Academic Plublishers, Netherlands.

SALMINEN P, HOKKANEN J and LAHDELMA R (1998) Comparing multicriteria methods in the context of environmental problems. Eur. J. Oper. Res. 104 (3) 485-496.

VINCKE P (1992) Multicriteria Decision-Aid. Wiley, Bruxelles, Belgium.

XIMENES R, SOUTHGATE B, SMITH PG and GUIMARÃES NETO L (2003) Socio-economic determinants of schistosomiasis in an urban area in the Northeast of Brazil. Rev. Panam. Salud Publica 14 (6) 409-421.

ZELENY M (1982) Multiple Criteria Decision Making. MacGraw-Hill, New York.

ZOPOUNIDIS C and DOUMPOS M (2002) Multi-criteria decision aid in financial decision making: Methodologies and literature review. J. Multicriteria Decis. Anal. 11 (4-5) 167-186. 
Available on website http://www.wrc.org.za ISSN 0378-4738 = Water SA Vol. 32 No. 2 April 2006 ISSN 1816-7950 = Water SA (on-line) 